\title{
Local Concerns on Plastic Bag Charge in Indonesia: Do we really care?
}

\author{
Nuzulul Kusuma Putri \\ Department of Health Policy and Administration \\ Faculty of Public Health, Universitas Airlangga \\ Surabaya, Indonesia \\ nuzululkusuma@fkm.unair.ac.id
}

\begin{abstract}
Indonesia is ranked second in a list of the countries which most contribute to plastic trash worldwide after China. Indonesia has restricted plastic bags in retail since March 2016, left behind by China which has already banned them since 2008 . This restriction policy regulates that the retail industry charges at least $\$ 0.02$ - for every single plastic bag that is used by its buyers depends on their region. This study analysed the public concerns on the implementation of a plastic bag charge policy. Public concerns on this policy were observed by analysing the largest online petition website in Indonesia. Nowadays, online petitions are the fastest media to communicate public support about some issues to the decision makers. The local concerns in each e-petition are determined by content analysis of the petition content, orientation, and its support of the environment. The local community has an enormous perspective on seeing this policy. Most of them already show this phenomenon as environmental orientation, even though there are still people who think about the economic value in the policy's trial period. There have been 5 mass petitions focused on the plastic bag charge policy. It makes up about $3.7 \%$ of the total petitions on issues of environmental health that have been posted on the e-petition website. The time that was when the petitions were issued was on the first month when the policy was executed. Not all of the petitions support the policy implementation due to the ambiguity of money transparency. Most of the petitions claimed that the regulator should increase the nominal charge. By the time the trial time of the regulations ended, the public concerns to do with this policy had decreased.
\end{abstract}

Keywords- local concern, plastic bag charge, policy, petition

\section{INTRODUCTION}

Plastic is widely known as being the most difficult degradable household waste. The huge amount of plastic household waste is contributed to by both traditional markets and grocery stores in Indonesia. As the 2nd country with most plastic trash in the world, Indonesia lately introduced a levy policy to minimise the number of consumable plastic trash in its population. There are many success stories about plastic bag charge regulations reducing plastic bag use. England, the latest country which has regulated a plastic charge on its retail industry since 2015 , has seen its plastic waste plummet by more than $85 \%$ after the introduction of a $5 p$ charge.

In China, the plastic-bag ban is to reduce the white pollution by two-thirds after its 2 year implementation [1]. Even though the policy is effective in minimising the number of plastic bags,
China is facing the truth that this policy is difficult to replicate for traditional markets. There is no formal regulation organising plastic bag distribution in traditional markets which means that there is no channel to enforce the charge policy. A similar policy has been implemented in Malaysia since 2011. It is proof that the policy is effective in making consumers avoid the use of plastic bags by $52.3 \%$ in a year [2]. In the next years of implementation, the effectiveness has become steady. The low rate of the charge has become the main cause for mobilising people to avoid the levy. This has also happened in South Africa. This policy has only succeeded in reducing consumption in the short term [3].

The introduction of this policy in Indonesia started in early 2016 through policy implementation during a three month trial period. During this period, the response of each stakeholder in relation to the plastic bag charge policy cycle was analysed for policy continuity issues. The government must consider the aspirations of the public in the policy cycle. Nowadays, information technology has become an effective media to transfer the aspirations of the common people to the decision maker [4]. In a democratic country, e-petitions likely reduce the barriers to citizens' participation in delivering the intended aspiration [5]. Some success stories among various countries have showed that how a massive population speaks up about their thinking will determine how the government and other populations react to the issue. The population in a country will find it easier to rise up against an issue if the public are made concerned by the government. This study aims to explore the public value of the plastic bag charge policy by identifying the public concerns on the implementation of a plastic bag charge policy during a trial period in Indonesia.

\section{METHOD}

As an exploratory study, all of the petitions concerning the plastic bag charge policy in Indonesia were collected from change.org, the biggest e-petition website accessed in Indonesia. The petitions were collected between Januarys until October 2016 with the keyword lingkungan, which means environment in English. There were 136 petitions retrieved by the use of this keyword but only eight petitions were concerned with plastic bag charges. Furthermore, these petitions were analysed through qualitative content analysis in order to assign the public value of each petition to the policy. The public value was analysed by mapping the characteristics of the petitions according to its 
published period, assertion, orientation, and its support towards the environment.

\section{THE UP AND DOWN OF CONCERN}

Some countries already charge for plastic bag use. Indonesia, as the second largest country contributing to plastic waste in the world, was left behind other countries regulating by plastic bag charges. Indonesia has regulated plastic bag charges on its retail sector since 21st February 2016. This was only the beginning of the trial regulation period. The trial period time of this regulation ended on the 31st May 2016. Retailers in every corner of Indonesia were required to charge their buyers Rp 200 equal to $\$ 0.02$ for every single plastic bag that they used. After the trial period ended, the plastic charge policy was no longer implemented. The retailer was permitted to give the plastic bags out for free. On the other hand, retailers were also permitted to continue to charge for the plastic bag. This policy depended on the retailer's policy. The national policy required every grocery store consumer to pay 200 IDR (\$0.02) for every plastic bag that they wanted for their purchase. The three month trial period of this policy was started in the middle of 2016 only for modern grocery stores. After this period ended, the national government delegated the continuance of this policy to the grocery store's own policy. Some stores continued the levy policy, but the rest of them chose to discontinue the policy.

\section{A. The Petition Mapping}

Petitions have always been a popular way for citizens to engage with local and national government [6]. The population will react positively to the environment when it is related to their living location [7]. It means that the most effective response to the environment will easily come out when it is connected with their daily lives. New waves of technology bring in the different insights of people, showing their aspiration. As a democratic country, Indonesia needs its citizens' aspiration in relation to every policy formulation. The aspiration of the citizen is represented by the House of Representatives. Today, the internet enables common people to share what they are thinking for every policy made by government. It simplifies the decision makers to know what exactly is aspired to by its citizen directly. With a big number of internet users, Indonesians also use the internet as form of media for expressing their opinions about a new policy including the plastic bag charge policy.

E-petitions are one of the more popular media to communicate the voice of the citizens. There are eight epetitions which discussed about policies regulating plastic on change.org. Change.org is the largest website mediating epetitions which is most accessed in Indonesia. All of the epetitions were created in 2013 - 2016. Based on this study, we can understand the local concerns to do with the policy by observing the public's aspiration in every policy period.
TABLE I. E-PETITION MAPPING

\begin{tabular}{|c|r|r|}
\hline & $\boldsymbol{n}$ & $\boldsymbol{\%}$ \\
\hline Periods & & \\
\hline Before trial period & 3 & $37.5 \%$ \\
\hline During trial period & 5 & $62.5 \%$ \\
\hline After trial period & & $0.0 \%$ \\
\hline Assertions & & \\
\hline increasing the charge nominal & 1 & $12.5 \%$ \\
\hline transparency of charge pooling & 1 & $12.5 \%$ \\
\hline policy existence & 4 & $50.0 \%$ \\
\hline other option beside charge & 1 & $12.5 \%$ \\
\hline plastic tax regulation & 1 & $12.5 \%$ \\
\hline & & \\
\hline Petition Orientation & & \\
\hline Environment & 5 & $62.5 \%$ \\
\hline Economy & 3 & $37.5 \%$ \\
\hline & & \\
\hline Support to Environment & & \\
\hline Negative & 1 & $12.5 \%$ \\
\hline Neutral & 1 & $12.5 \%$ \\
\hline Positive & 6 & $75.0 \%$ \\
\hline
\end{tabular}

E-petitions about the plastic bag charge in Indonesia were already issued long before the regulation was implemented. This indicates that Indonesian people are already aware of the urgency of its regulation. During the trial period, people are more aware about other issues. The e-petitions' frequency increases regarding the next step of the policy cycle. No existence of e-petitions after the trial period ends means that people tend to neglect policies when there is no trigger.

Mass media is the most possible trigger which can attract concerns. As part of Web 2.0, an e-petition, build for two-way communication, then enables more citizens to participate in decision-making in the country directly [8]. During the trial period, logically there is abundant news about the plastic bag charge. Local concerns on plastic bag issues are still driven by the excitement of the media who reported frequently during the trial period.

The local community has an enormous perspective about seeing in this policy. Most of them already show this phenomenon as being an environmental orientation, even though there are still people thinking about the economic value. The economic value has arisen as their concern is focused on other policies which regulate the value-added tax on recycling stuff. The majority of e-petitions tend to support the go green campaign. Only one e-petition was opposed to environment sustainability.

TABLE II. THE TIME CYCLE OF LOCAL CONCERN

\begin{tabular}{|l|r|r|r|}
\hline & \multicolumn{1}{|c|}{ Before } & During & After \\
\hline $\begin{array}{l}\text { Increasing the charge } \\
\text { nominal }\end{array}$ & 0 & 1 & 0 \\
\hline $\begin{array}{l}\text { Transparency of charge } \\
\text { pooling }\end{array}$ & 0 & 1 & 0 \\
\hline Policy existence & 3 & 1 & 0 \\
\hline Other option beside charge & 0 & 1 & 0 \\
\hline Plastic tax regulation & 0 & 1 & 0 \\
\hline Total & 3 & 5 & 0 \\
\hline
\end{tabular}


The time cycle of local concerns shows at least two meaningful analyses. First, local concerns are correlated with momentum. There were more e-petitions signed in the trial period which exhibits that people tend to react more actively in the trial period. Information exposure in mass media about the plastic bag charge brings up the euphoria of the audience to show their perspective of the current issue. Moreover, epetitions issued on time were mostly in the trial period of February and March. This transpired after the national commemoration day of caring for trash which is celebrated on 21st February, then it will be the ideal time to hold a massive campaign about plastic trash.

Second, the time cycle also effects the assertions of the epetitions. In the early time cycle, there are community concerns to do with the existence of new regulations on plastic bag use. Before the regulation existed, most of the community was concern about encouraging the government to execute the plastic charge. People demand a legal law that is able to control plastic bag consumption. After this assertion has been fulfilled through the implementation of plastic bag charges in the trial period, people go on to ask about further issues regarding the improvement of the trial regulation.

The successfulness of the e-petitions as an inspiration channel is proofed throughout the time cycle. Various aspirations were delivered during the trial period. The community has already experienced the plastic bag charge which then inspires them through the e-petition.

In the trial period, more people noticed not only about the existence of the plastic bag charge policy. The community was also aware about how the regulation will more effectively restrict the number of plastic bags used. People suggested that the government should be consistent in implementing the regulation by producing an Act rather than a government regulation.

The effective economic point of the charge price is discussed in two e-petitions which suggests the way to succeed at the policy. These consider the government to increase the rate of the charge. People think that a low nominal of charge cannot decrease the people's willingness to consume plastic bags. Rather than improving the rate, other e-petition concerns suggest that the government finds other solutions that could make the plastic bag charge policy more effective. In a neutral position, this e-petition precisely invites the community to use permanent bags for groceries to push down on the number of plastic bags used.

On the other hand, not all of the e-petitions support the plastic bag charge policy. There is an e-petition that tends to encounter the spirit of the policy. This e-petition is questioning what will happen with the money raised through the plastic bag charge. The unclear regulation about the allocation of what the money should be used for makes people react negatively to the plastic bag charge policy. People are also questioning who should manage the money. People who do not fully support the regulation have argued that the policy has abandoned the wrong target. Consumers should not be charged because a bag should be prepared by the retailer. This group thinks that a bag for shopping is the retailer's responsibility.

At the end of the time cycle, local concerns also tend to end. No more e-petitions were published after the momentum of the trial period ended. This possibly happened because people were confused as to whether the policy still existed or not. Unclear statements from the regulator about the continuity of the trial period or changing to a permanent policy was not reported massively in the mass media.

\section{B. Government-citizens Relationship}

In web 2.0, citizens do not merely have the role as a customer of public policies. The coproduction between the government and its citizens is naturally created through interactions via the internet. E-petition websites are one of media available for citizens to deliver what they think about issues in the country. Local concerns to do with the plastic bag charge that were delivered through e-petition websites should be considered by the government in determining the future of the policy.

This study shows that most of the citizens reacted positively to the existence of the plastic bag charge policy. The high concern of the citizens should be considered as an opportunity for the government to continue the policy that has already been tested. A study conducted by Linders (2012) [9] showed that social media scaled up the possibility of people showing their participation in relation to the functioning of the government. Internet-based media is a powerful set of tools to reinvent government-citizen relationships [10]. This brings in the possibility that when the government does not accommodate what is already asserted by its citizens for the improvement of the plastic bag charge, it could ruin the government-citizen relationship.

The time cycle of the plastic bag charge policy shows that momentum is the booster in triggering how the community reacts to an issue. This time cycle characteristic should be taken into account when the government tests the citizens' acceptance of a policy. The government should participate more actively in reacting to the local concerns which are delivered in e-petitions. The government's response should also be delivered in perfect timing with the momentum. A good implementation strategy is necessary to realise these benefits and to avoid risks.

\section{CONCLUSION}

The plastic bag charge policy was regulated by the government to ensure that its citizens will be wiser in consuming plastic. The trial period of this policy showed us that the existence of local concerns was first identified as public demand in how the government should regulate the uncontrolled plastic bag utilisation. Policy momentum should be considered as a communication strategy in order to make the public better receive the policy. Moreover, the government 
should realise that policy sustainability should be built by not only public acceptance toward the policy, but also by government initiatives about building communication in socialising the policy itself.

\section{ACKNOWLEDGMENT}

We would like to share our appreciation towards the Faculty of Public Health of the Universitas Airlangga for financial support during the data analysis. We also would like to thank the Department of Health Policy and Administration Faculty of Public Health Universitas Airlangga for the academic suggestion in writing the paper.

\section{REFERENCES}

[1.] Zhu Q. An appraisal and analysis of the law of "Plastic-Bag Ban." Energy Procedia. 2011;5:2516-21.

[2.] Asmuni S, Hussin NB, Khalili JM, Zain ZM. Public Participation and Effectiveness of the no Plastic Bag Day Program in Malaysia. Procedia - Soc Behav Sci. Elsevier B.V.; 2015;168:328-40.

[3.] Dikgang J, Leiman A, Visser M. Analysis of the plastic-bag levy in South Africa. Resour Conserv Recycl. Elsevier B.V.; 2012;66:59-65.
[4.] Rivers N, Shenstone-Harris S, Young N. Using nudges to reduce waste? The case of Toronto's plastic bag levy. J Environ Manage. Elsevier Ltd; 2017;188(2017):153-62.

[5.] Oni A, Ayo CK, Oni S, Duruji M. Electronic petition and democratic participation in Nigeria. Proc Eur Conf e-Government, ECEG. 2015;2015-Janua:223-30.

[6.] Toland J. E-petitions in local government: the case of Wellington city council. Int Reports socio-informatics. 2011;2(Huff 1996):15-22.

[7.] Hinds J, Sparks P. Engaging with the natural environment: The role of affective connection and identity. J Environ Psychol. 2008;28(2):109-20.

[8.] Leong P. Political Communication in Malaysia: A Study on the Use of New Media in Politics. JeDEM [Internet]. 2015;7(1):46-71. Available from: http://www.jedem.org

[9.] Linders D. From e-government to we-government: Defining a typology for citizen coproduction in the age of social media. Gov Inf Q [Internet]. Elsevier Inc.; 2012;29(4):446-54. Available from: http://dx.doi.org/10.1016/j.giq.2012.06.003

[10.] Picazo-Vela S, Gutiérrez-Martínez I, Luna-Reyes LF. Understanding risks, benefits, and strategic alternatives of social media applications in the public sector. Gov Inf $\mathrm{Q}$ [Internet]. Elsevier Inc.; 2012;29(4):504-11. Available from: http://dx.doi.org/10.1016/j.giq.2012.07.002 